\title{
SENTIDOS AO SEU VIVER: JESSY CHEREM UMA EDUCADORA EM TRÂNSITO (SANTA CATARINA, 1960-1980)
}

SUSANE DA COSTA WASCHINEWSKI

https://orcid.org/0000-0002-9024-0539

Universidade do Estado de Santa Catarina

\section{MARIA TERESA SANTOS CUNHA}

http://orcid.org/0000-0001-6200-6713

Universidade do Estado de Santa Catarina

RESUMO O texto pretende apresentar aspectos e construir sentidos sobre a trajetória de Jessy Cherem (1929-2014), uma professora catarinense que protagonizou deslocamentos - tanto em âmbito nacional como estadual - que tiveram como intuito tanto seu aperfeiçoamento profissional como sua atuação posteriormente dedicada à formação de educadores e diretores escolares em diversos municípios catarinenses e em outros estados brasileiros. Analisar os deslocamentos dessa profissional criou possibilidades para observar brechas para recompor questões mais gerais sobre campanhas de formação de professores, como para problematizar a presença de mulheres viajantes e das redes que fomentaram em seu trânsito. Considerando as potencialidades e limites do tema, a investigação contou com documentos que integram o seu arquivo pessoal, entrecruzados com as próprias entrevistas dadas em vida pela professora sobre esse tema. Palavras-chave: Formação de educadores. Trajetórias. Mulheres viajantes. Arquivos pessoais.

\section{ABSTRACT SENSES TO HER LIFE: JESSY CHEREM AN EDUCATOR IN TRANSIT (SANTA CATARINA, 1960-1980)}

The text intends to present aspects and build meanings about the trajectory of Jessy Cherem (1929-2014), a Santa Catarina teacher who led displacements - both nationally and statewide - that aimed both at her professional development and at her later performance dedicated to educators and school principals training in several municipalities of Santa Catarina and in other Brazilian states. Analyzing the displacement of this professional created possibilities to ob- 
serve gaps both to recompose more general questions about teacher training campaigns and to problematize the presence of female travelers and the networks they fostered in their transit. Considering the potentialities and limits of the theme, the research included documents that are part of her personal archive, interspersed with the interviews given by this teacher in life, about this theme.

Keywords: Training of educators. Trajectories. Women travelers. Personal archives.

\section{RESUMEN SENTIDOS A SU VIDA: JESSY CHEREM UN EDUCATOR EN TRANSIT (SANTA CATARINA, 1960-1980)}

El texto pretende presentar aspectos y construir sentidos sobre la trayectoria de Jessy Cherem (1929-2014), una profesora de Santa Catarina que protagonizó desplazamientos - a nivel nacional como estatal - cuyo propósito era tanto su mejora profesional como su acción dedicada a la formación de maestros y directores de escuelas en varios municipios de Santa Catarina y otros estados brasileños. Analizar los desplazamientos de esta profesional ha creado posibilidades para observar lagunas para recomponer preguntas más generales sobre las campañas de formación de profesores como para problematizar la presencia de mujeres viajeras y las redes que han fomentado su tránsito. Teniendo en cuenta la potencialidad y los límites del tema, la investigación incluyó documentos que integran su archivo personal, entrelazados con las entrevistas dadas en la vida, por la maestra, sobre este tema.

Palabras clave: Formación de educadores. Trayectorias, Mujeres viajeras. Archivos personales.

\section{Introdução}

Jessy Cherem, mulher, esposa, professora, gestora, intelectual e mãe, dedicou-se ao aperfeiçoamento de outros professores no estado de Santa Catarina. Pouco lembrada e menos ainda mencionada na história da educação catarinense, possui uma trajetória possivel de relacionar com a de outras professoras e intelectuais que, assim como ela, viajaram a trabalho entre os anos de 1960 a 1980. Esses deslocamentos tornam-se objeto de estudo, pois o que "[...] nos interessa é acompanhar os passos de uma trajetória singular que suscite inquietações, dúvidas e incertezas que também possam interessar a todos aqueles preocupados com os problemas e a relevância da pesquisa e da escrita histórica" (AVELAR; SCHMIDT, 2012, p. 77). Assim, este artigo tem por objetivo refletir e, dessa forma, construir sentidos sobre experiências vivenciadas por Jessy Cherem ao longo de suas viagens, longe de sua cidade, familiares, filhos e amores, e, a partir disso, problematizar como esses deslocamentos contribuíram para constituir um alargamento do capital simbólico, proporcionando novos contornos à atuação profissional dessa mulher e professora. 
Ao buscar aproximação com essas questões, não se tem como objetivo apresentar uma linearidade, muito menos uma versão final ou uma cronologia sobre a vida da personagem. Objetiva-se alcançar questões sobre a história de vida de uma professora cuja atuação percorreu múltiplos espaços e diferentes tempos, sobre os quais produziu documentos em diferentes suportes - presentes e reconhecidos em seus arquivos pessoais. Ao mesmo tempo, ilumina-se esse percurso profissional com duas entrevistas dadas por ela, que integram lembranças daqueles(as) com que conviveu em diferentes esferas e locais de atuação. Trata-se, enfim, de um trabalho que traz "[...] experiências de formação no contexto do movimento biográfico que vem se consolidando no território das histórias vida [...] que toma o sujeito e sua vida como princípios fundantes" (SOUZA, 2011, p. 14).

Bourdieu (1996), em seu estudo “A ilusão biográfica", considera que uma trajetória de vida é descontínua e fragmentada, envolta em diferentes espaços e tempos, os quais exigem movimentos de construção e desconstrução. Corroborando com as ideias do autor, considera-se Jessy Cherem em seus diferentes espaços, títulos e fazeres de sua atuação profissional: "professora", "gestora", "formadora", "idealizadora" em uma "[...] série de posições sucessivamente ocupadas por um mesmo agente ou por um mesmo grupo de agentes em espaços sucessivos" (BOURDIEU, 1996, p. 189). Por meio de seus rastros, trabalha-se com elementos de sua trajetória profissional correlacionada ao cenário educacional catarinense e com vestígios de histórias vividas também por outras professoras, que percorreram lugares, espaços, e estabeleceram relações e redes de sociabilidades, ou seja, momentos da atuação profissional que demonstram as "[...] colocações e deslocamentos no espaço social" (BOURDIEU, 1996, p. 190).
Jessy Cherem produziu e acumulou documentos ao longo de sua trajetória profissional que foram selecionados e organizados por ela própria; portanto, de acordo com os critérios que definiu. 0 trânsito constante entre cidades e estados fez com que esse acúmulo documental fosse controlado, recortando momentos mais significativos de sua vida profissional. Além de momentos pessoais, seu arquivo pessoal traz documentos de diferentes suportes, como álbuns, fotos, cartas, cartões postais, relatórios, certificados e recortes de jornais reunidos e selecionados que "[...] não apenas se referem aos negócios e atividades formais de caráter oficial do indivíduo, como também uma importante fonte de informações sobre a vida e as relações cotidianas e pessoais, quase que por sua própria natureza" (HOBBS, 2018, p. 26). Esses documentos analisados permitem construir vários sentidos para uma mesma pessoa, entrecruzar contextos políticos e educacionais, diferentes locais de atuação, e considerar seus guardados "[...] como meio de acesso [à] trajetória pessoal do titular" (HEYMANN, 2012, p. 14). Nesse sentido, para melhor compreender as problematizações objetivadas neste texto, faz-se necessário conhecer alguns aspectos biográficos da personagem pesquisada.

\section{Um modo de apresentar Jessy \\ Cherem}

Figura 1 - Jessy Cherem

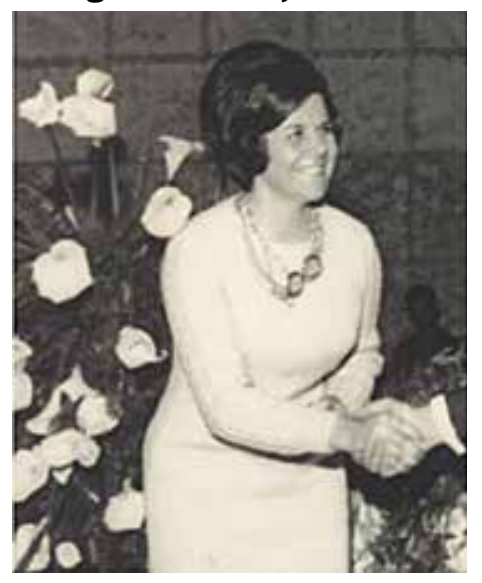

Fonte: acervo pessoal de Jessy Cherem (1965). 
Jessy Cherem nasceu no município de Tijucas, Santa Catarina, em 24 de setembro de 1929 e faleceu ${ }^{1}$ em Florianópolis, em 2014, aos 85 anos de idade. Ainda em seus primeiros meses de vida, seus pais, Nila Cherem e José Cherem (de origem libanesa), que eram comerciantes, mudaram-se para Florianópolis, onde passaram a residir na Rua Almirante Lamego, no centro da cidade. A casa comprada pela família foi demolida para dar lugar a um edificio que, atualmente, leva o nome de sua mãe, Nila Cherem.

Estudante normalista do imponente Colégio Coração de Jesus (CCJ), ${ }^{2}$ localizado na região central da cidade de Florianópolis, Jessy Cherem pertencia a uma família tradicional dos círculos sociais florianopolitanos, ${ }^{3}$ que se caracterizam pela presença daqueles "grupos que parecem ocupar o 'topo' de 'estruturas de autoridades ou de distribuição de recursos"' (HEINZ, 2006, p. 7). Esse é o caso de Jessy Cherem Stocco, cercada por dois sobrenomes de "notoriedade" na vida pública política e empresarial de Florianópolis, já que casou com um médico - Hamilton Pinto Stocco.

Estudou durante sete anos no (C), onde recebeu o título de professora no ano de 1948. Durante o período em que era estudante, le-

1 Seu falecimento foi noticiado com o título "Jessy era exemplo de coragem e fé" no portal eletrônico ClicRBS de Santa Catarina. Disponivel em: http://wp.clicrbs. com.br/obituarioan/2014/11/05/jessy-era-exemplode-coragem-e-fe. Acesso em: 3 jul. 2018.

2 O CCJ é uma instituição de identidade confessional católica de ensino privado. Foi fundado no fim do século XIX (1898) e se tornou referência educacional catarinense pela tradição de formação de alunos(as) e professores(as). No ano de 2006, o CCJ passou a ser administrado pela Associação Franciscana de Ensino Senhor Bom Jesus (AFESBJ) e passou a se chamar Colégio Bom Jesus (CBJ) (COELHO JUNIOR, 2018).

3 De acordo com May (1998, p. 45), no início do século XX, a formação das "elites" políticas em Santa Catarina ocorre, pois, com os indivíduos "[...] ligados entre si no dia a dia em função da parceria nos negócios, da liderança em associações de classe, ou [...] através das atividades desempenhadas na esfera política". Além dos vínculos que se estabeleciam nas atividades comerciais e políticas, a união de famílias era uma característica comum para a constituição de redes de favores. cionava gratuitamente para as crianças asiladas da Sociedade Divina Providência (SDP), ${ }^{4}$ iniciando, assim, suas primeiras experiências em sala de aula. Depois de formada, foi convidada para lecionar no CCJ em Florianópolis, onde estudou, e lá permaneceu dois anos lecionando em turma pré-ginasial e de primeiro ginasial.

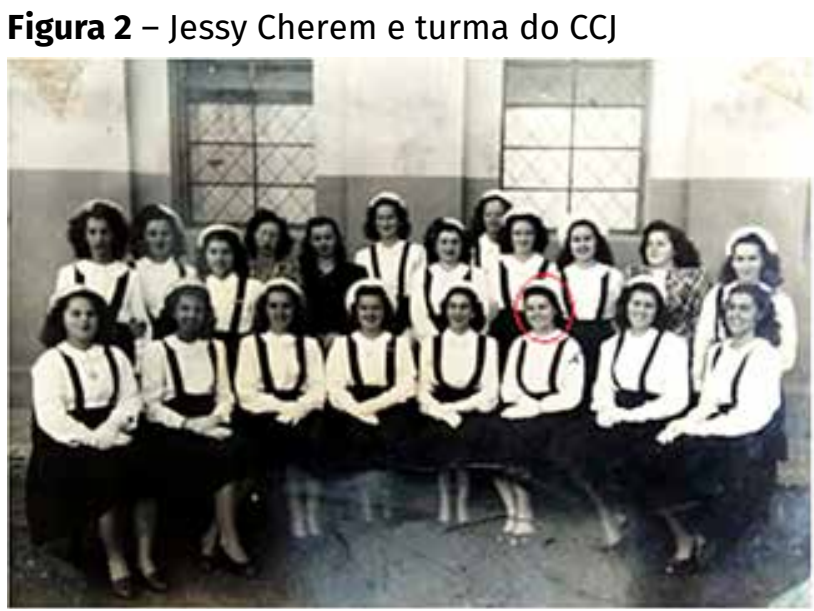

Fonte: arquivo pessoal de Jessy Cherem (s/d). Álbum com capa de madeira.

O ingresso no magistério não surgiu como uma "vocação que vem de infância", mas sim pelas circunstâncias: “[...] naquela época ou era professora ou ficava em casa tocando piano. Então meu pai gostou muito de eu ser professora, ainda mais do Colégio Coração de Jesus que naquela época era 'o' colégio". 0 testemunho da entrevistada nos remete ao estudo de Maurício (2009, p. 135), para quem:

As instituições formadoras são lembranças significativas para a opção pelo magistério. 0 decorrer do curso, os estágios, o contato com professores formadores, a primeira entrada em sala de aula, o encantamento do contato com

4 A instituição pertence à Congregação das Irmãs da Divina Providência, oriunda da Alemanha, que mantém em Santa Catarina hospitais, colégios e obras sociais. A instituição destina bolsas de estudos e promove projetos socioeducacionais que atendem à comunidade carente. Está localizada ao lado do CCJ. Disponivel em: http://divinaprovidencia.org.br/noticias/2017/10/25/ congregao-das-irms-da-divina-providncia-completa175-anos. Acesso em: 4 out. 2019.

5 Entrevista anteriormente mencionada. 
a criança, são todas circunstâncias que propiciam a opção pelo magistério, mesmo que não tenha sido um sonho de infância.

As alunas normalistas tinham em suas professoras modelos a contribuir para a escolha ao magistério, ao mesmo tempo em que serviam de padrão para a sua formação. A atuação inicial das normalistas partia da prática experimental sob a tutela do(a) professor(a) titular (SILVA, 2004). Como testemunha dessa metodologia, Jessy Cherem, em entrevista, ainda sem concluir o curso normal, esclarece que já ministrava aulas para as crianças asiladas no CC), demonstrando assim que já possuía exercício na docência antes mesmo de seguir o magistério. A narrativa da personagem apresenta aspectos importantes sobre a presença das mulheres no magistério catarinense, não raro desnaturalizando a representação do magistério como vocação essencialmente feminina.

O processo de feminização do magistério está inserido nas transformações econômicas e sociais em escala internacional, que produziram efeito na configuração educacional em diferentes países (VIANNA, 2013). A essas transformações, somaram-se tanto questões relativas às necessidades econômicas como também à organização das mulheres ${ }^{6}$ para 0 reconhecimento e participação no "mundo do trabalho". Ser professora, para Jessy, parecia ter sido a melhor escolha a fazer, como uma forma de não ficar reclusa à esfera privada, ao mesmo tempo em que a profissão era bemvista por seu pai e pela sociedade naqueles anos. Foi por meio de sua "opção" pelo magistério que iniciou sua trajetória profissional, o que permite pensar que, assim como ela, muitas outras mulheres de sua geração aderiram à profissão docente como caminho possivel para não ficar reclusa ao ambiente doméstico

6 Em especial as mulheres brancas e de classe sociais mais favorecidas, pois as mulheres negras e pobres já integravam, desde finais do século XIX, o mercado de trabalho informal (PEDRO, 1994). e até ingressar no mercado de trabalho, que se abria para o magistério feminino.

Após aceitar o convite para lecionar no CCJ, Jessy permaneceu na instituição por dois anos, dando aulas para turmas pré-ginasial e primeiro ginasial, e só saiu "[...] de lá para me casar".7 Casou-se no ano de 1951, aos 22 anos de idade, com o médico e major da Polícia Militar Hamilton Pinto Stocco, passando a residir por quase sete anos em Curitiba, no Paraná. Nos primeiros anos após seu casamento, fez uma pausa em sua profissão: "[...] deixei o magistério, por algum tempo". Nesse período, teve dois filhos. Mesmo afastada das salas de aula, Jessy manteve contato com o CCJ, o que possibilitou lecionar aulas de reforço em sua residência para cerca de 30 alunas. Além disso, passou a ministrar no curso científico de educação, também no Colégio da Divina Providência. Segundo Jessy, as disciplinas tratavam educação sobre a vida na sociedade. "Colaborei também como conferencista no Colégio Coração de Jesus [em Curitiba]", atendendo a "grupos de casais [noivos] que desejassem aprimorar sua formação para o casamento".

Nos anos em que permaneceu em Curitiba, recém-casada, dividiu-se entre cuidar dos fiIhos e ministrar aulas particulares em sua casa e, posteriormente, no próprio colégio. Depois de alguns anos (1958), voltou a residir na capital catarinense: "Por motivos particulares, me separei do meu marido e voltei a morar em Florianópolis", momento em que iniciou uma nova etapa em sua trajetória.

Em 1962, passou a integrar o quadro de técnicos educacionais da Secretaria de Educação do estado de Santa Catarina. Em 1963, recebeu um convite para realizar um curso de aperfeiçoamento (1956-1964) como bolsista no Pro-

7 Este e os trechos citados sem referência a seguir correspondem a falas de Jessy Cherem em entrevista concedida a Angélica da Silva Goulart e Giani Rabelo, em Florianópolis, no dia 18 de fevereiro de 2009.

8 Alguns desses aspectos foram pesquisados por Waschineweski (2017). 
grama de Assistência Brasileiro-Americana ao Ensino Elementar em colaboração com Instituto Nacional de Estudos e Pesquisas Educacionais Anísio Teixeira (PABAEE-Inep), quando permaneceu um ano em Minas Gerais realizando cursos e especializando-se em educação pré-escolar, com estágios no Rio de Janeiro e em escolas de Minas Gerais, que tinham como objetivo conhecer diferentes experiências educacionais.

O PABAEE-Inep foi um programa firmado a partir de um acordo entre Brasil e Estados Unidos que tinha como objetivo promover 0 aperfeiçoamento dos(as) professores(as), diretores(as) e técnicos(as) educacionais brasileiros(as) e também de outros países latino-americanos onde o convênio foi estabelecido. Além de um discurso de "ajuda" aos problemas educacionais, o programa considerava o quadro educacional brasileiro problemático, responsabilizando a formação de professores(as) como principal questão a ser superada, sem considerar uma série de outros fatores. Em sintese, tinha como prioridades:

I. Formar quadros de instrutores de professores de ensino normal para as diversas das Escolas Normais mais importantes do Brasil. 2. Elaborar, publicar e adquirir textos didáticos tanto para as Escolas Normais como para as Elementares. 3. Enviar aos Estados Unidos, pelo período de um ano, na qualidade de bolsistas, cinco grupos de instrutores de Professôres de ensino normal e elementar, recrutados nas regiões representativas do Brasil, que ao regressarem, serão contratados pelas respectivas Escolas Normais para integrem os quadros de instrutores de professôres pelo período mínimo de dois anos (DIÁRIO OFICIAL DA UNIÃO, 6 de março de 1957. Seção I, p. 5074).

Com o intuito de melhorar aspectos educacionais, o estado catarinense seleciona Jessy Cherem e possivelmente outras professoras ${ }^{9}$ -

9 De acordo com o relatório do PABAEE-Inep, de 1959 a 1964, Santa Catarina enviou 19 professores para os cursos de aperfeiçoamento. Até o momento, esses o que expressa confiança ou vínculos nas redes de interação em que ela e seus familiares estavam envolvidos. As professoras enviadas para os cursos de aperfeiçoamento tinham como responsabilidade tornar-se especialistas em alguns temas educacionais e, posteriormente, atuar em seus respectivos estados, aplicando os conhecimentos adquiridos em prol da meIhoria do quadro educacional.

Em Santa Catarina, no início da década de 1960, havia muitos aspectos educacionais problemáticos (assim como em outros estados): elevados índices de reprovação, baixa oportunidade de matrícula e o abandono escolar, que contribuíam para as estatísticas negativas. As condições para esses dados estavam relacionadas à insuficiência de instituições responsáveis pela formação de professores: "No que tange ao professor, à sua formação, o quadro não era menos desalentador: 5.500 das 9.000 professoras de 1a a 4a série que atuavam no Estado, no ano de 1960, não possuíam qualquer habilitação para o exercício do magistério" (AURAS, 1998, p. 31).

Assim como Jessy Cherem, outras professoras de diversos estados brasileiros foram selecionadas para realizar os cursos do PABAEE - Inep, que buscavam incorporar na educação brasileira sintonias com as propostas educacionais apregoadas pelo programa. A participação dessas professoras pode ser vista como algo pouco convencional para os padrões da época, ao se tratar de formas de alargamento dos espaços de viagens de longas distâncias e duração, já que essas mulheres permaneciam um ano nas dependências do programa. Muitas, após concluírem os cursos do PABAEE-Inep no Brasil, foram selecionadas para conhecer a sede nos Estados Unidos, permanecendo fora do país entre seis meses e um ano.

A ida de Jessy Cherem à capital mineira teve como objetivo seu aperfeiçoamento em

professores não foram identificados. 
educação pré-escolar. Durante o ano em que permaneceu em Belo Horizonte, teve aulas, visitou experiências educacionais em escolas modelos do PABAEE-Inep, participou de palestras e seminários e esteve em contato com professores e intelectuais da educação de diversas regiões brasileiras e também de outros países. Nesse sentido, podemos pensar nos deslocamentos de Jessy Cherem além da questão geográfica, como momento de transição no campo da aquisição de conhecimento, na constituição de seu capital cultural.

Em relação à escolha da educação pré-escolar entre as múltiplas possibilidades, considera-se o quadro educacional dos anos de 1960, o qual apresentava uma carência referente à oferta de instituições educacionais destinadas às crianças pequenas. Segundo Batista (2013), em Santa Catarina, a presença de iniciativas voltadas para a educação das crianças ocorria, em grande parte, por meio das atividades de caráter social e assistencial, vinculadas às mulheres geralmente das congregações católicas, construindo uma docência vinculada aos princípios religiosos. De acordo com a autora, nas primeiras décadas do século XX, as iniciativas de implantação de jardins de infância em Santa Catarina não ocorriam por intermédio do estado, e sim pela ação particular e religiosa, ou seja, o estado assumiu posição coadjuvante frente à implantação de instituições de educação destinada às crianças pequenas (BATISTA, 2013).

Em Santa Catarina, a partir da Reforma Trindade (de 1935 a 1945), ocorreu a alteração da escola normal para instituto de educação, passando este a oportunizar ofertas de cursos de jardins de infância. Além disso, após a iniciativa de criação de jardim de infância nos institutos de educação, apenas dois municípios em Santa Catarina, Florianópolis e Lages, adequaram-se ao o Decreto no 713 , de 5 de janeiro de 1935 . Ou seja, mesmo conside- rando a proposta "inovadora", podemos inferir que diversos fatores pesaram para que não houvesse a concretização dos jardins de infância por iniciativa estatal: a possivel falta de professores formados, a destinação de espaço físico e a própria falta de orientações mais consistentes para constituição dessas instituições.

A partir do Decreto no 3735 , de 17 de dezembro de 1946, tendo o professor Elpídio Barbosa como um de seus mentores, houve a regulamentação dos estabelecimentos do ensino primário no estado de Santa Catarina (CUNHA, 2017, p. 194-195), propiciando iniciativas que vão configurando a relação de proximidade entre jardim de infância e ensino primário sendo que a expressão "pré-primário" se configura por meio do seguinte artigo: “Art. 60 - Os cursos de jardim da infância se articularão com o curso primário elementar". Com iniciativas tímidas e lentas, por um longo tempo, o espaço ficou aberto à intervenção das instituições particulares e congregações religiosas, que construíram importantes experiências educacionais. Assim que a ação do estado começava a ficar mais ordenada, principalmente a partir da Lei de Diretrizes e Bases da Educação Nacional (LDBEN) de 1961, passando a ocorrer a ampliação das iniciativas estatais e, com isso, a intensificação dos debates educacionais em torno dos métodos que deveriam ser aprendidos nessas instituições.

É no contexto dos anos de 1960, em consonância com essas demandas, que Jessy Cherem e muitas outras professoras viajaram em busca de aperfeiçoamento. É importante refletir que, nessa década, ocorriam no país profundas mudanças culturais e vivia-se a efervescência dos discursos que pautavam a modernização e das ideias desenvolvimentistas. Esses anos ficaram conhecidos como "era de ouro" ou "anos dourados". De acordo com Gomes (1991), eram anos que indicavam a crença do desenvolvi- 
mento constante e necessário. Foram tempos em que reinava o espírito otimista, democrata e empreendedor, sob a liderança do governo de Juscelino Kubitschek (1956-1961).

Figura 3 - Professoras no curso de aperfeiçoamento do PABAEE, em Belo Horizonte

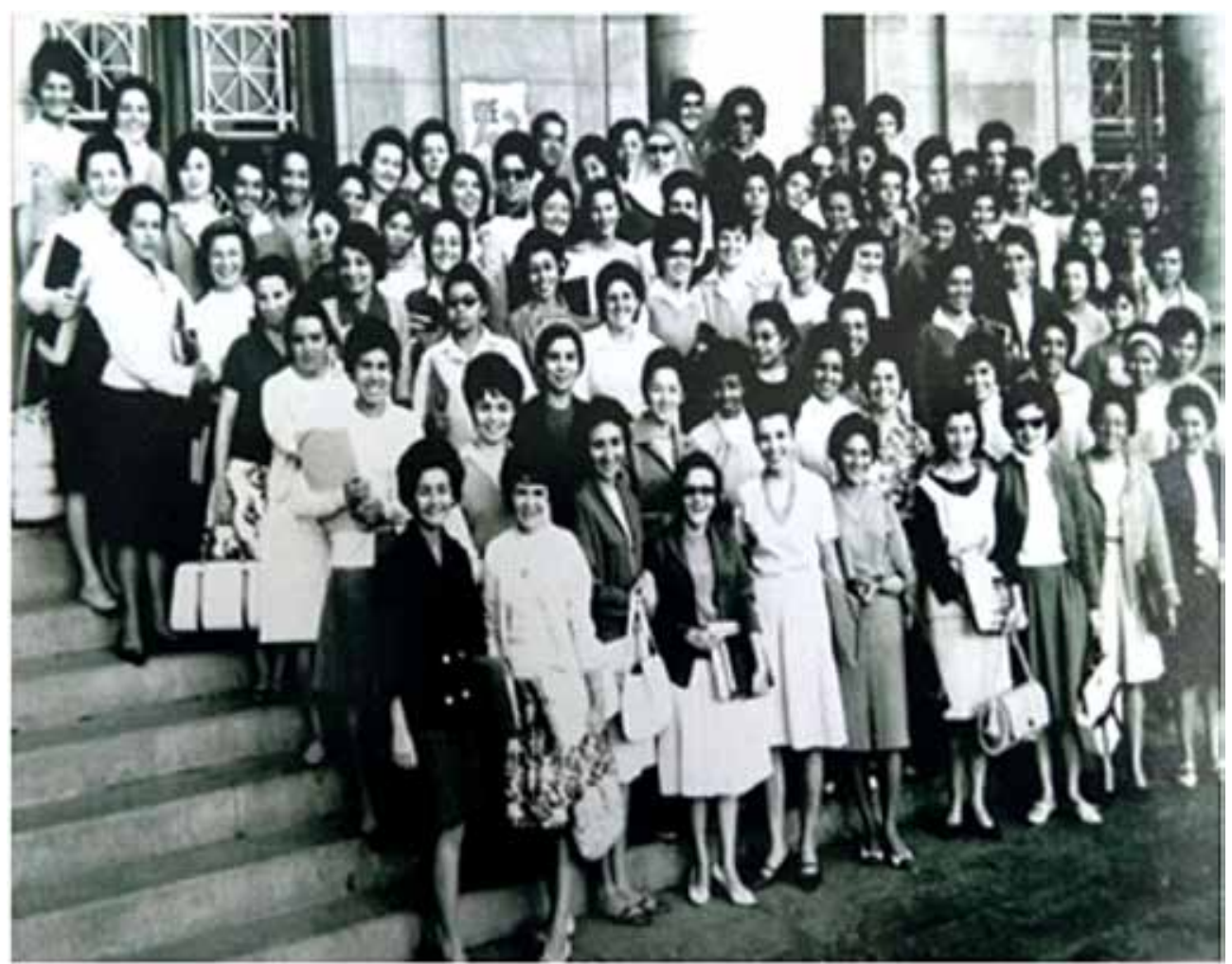

Fonte: arquivo pessoal de Jessy Cherem (s/d).

O trânsito dessas professoras ocorreu em um período no qual a palavra de ordem era a modernização do país, sendo que suas "[..] viagem comporta[m] assim deslocamento geográfico inerentes ao movimento de partida e chegada, se desdobrando ainda nos deslocamentos sociais daí advindos" (CHAMON, 2015, p. 61). Ou seja, além do ato de viajar, ocorreu o aumento do capital simbólico de cada uma das viajantes, ampliando suas relações e interações sociais e individuais, contribuindo para que essas professoras se tornassem representantes da modernização educacional e propagassem os conhecimentos, lá adquiridos, em seus respectivos estados.

Após concluir seu curso de aperfeiçoamento, Jessy Cherem retornou a Florianópolis, Santa Catarina (1963), e, assim como as demais bolsistas do PABAEE-Inep, prestou serviços durante dois anos, como forma de pagamen- to de sua bolsa, atuando na formação de professores para o aperfeiçoamento e a difusão dos conhecimentos lá adquiridos. Essa experiência bem-sucedida reverberou no convite recebido em 1964 para atuar como diretora de educação e assistência social no município de Criciúma, estabelecendo residência nessa cidade até 1967.10 Além disso, atuou nos Cursos de Aperfeiçoamento para Professores Rurais (Capru), deslocando-se frequentemente a diversas cidades do interior de Santa Catarina.

10 Em Criciúma, na região sul de Santa Catarina, lecionou no Colégio Madre Tereza Michel e residiu inicialmente nas dependências da instituição, em um quarto organizado pelas irmãs e destinado à sua estadia. Também ministrou aulas no Colégio São Bento e no Colégio Marista, todas escolas confessionais e particulares. Em paralelo, atuou como idealizadora do primeiro jardim de infância particular da cidade, que se chamou Jardim de Infância Pequeno Príncipe. Com essa implantação, Jessy pôde aplicar os conhecimentos adquiridos durante o curso de aperfeiçoamento do PABAEE, conforme informam seus arquivos pessoais. 
Durante os anos de 1977 a 1987, foi diretora do Museu Histórico de Santa Catarina (MHSC), durante a gestão do governador Antônio Carlos Konder Reis, e, concomitantemente ao exercício do cargo, graduou-se em licenciatura em Educação Artística na Universidade do Estado de Santa Catarina (UDESC), formando-se em julho de $1980 .{ }^{11}$ Nesse período como primeira diretora do MHSC, fez inúmeras viagens em busca de aperfeiçoamento nesse campo, além de realizar estágios no Museu Histórico do Rio de Janeiro e Museu Nacional, com o intuito de conhecer diferentes museus, e outras viagens destinadas a coletar peças para o MHSC.

\section{Diversas viagens, múltiplos trânsitos, vários sentidos}

Viajar, pôr-se em movimento, ato de partir de um lugar para outro, transitar, deslocarse. Jessy Cherem realizou viagens de curtas e longas distâncias e durações. Suas viagens mencionadas nesta pesquisa tiveram como fim sua formação ou destinaram-se à formação de outros(as) professores(as). Tais constatações emergem e podem ser vistas por meio dos documentos que compõem seu arquivo pessoal: pode-se, enfim, considerar que ela esteve em constante trânsito: visitando escolas e instituições educacionais, participando de eventos, ministrando e atuando na formação de professores(as). Possivelmente, esse trânsito converteu-se em:

[..] capitais acumulados e adquiridos com conhecimentos específicos de um campo thes conferiam poder e reservava-lhes o direito de estarem frente às questões e decisões educacionais. Isto faz com que as viagens carreguem uma aura diferenciando uns em relação a outros. Aqueles que viajavam tinham um elemento de distinção. Conquistavam novos conheci-

11 Conforme documento consultado em agosto de 2018 na Secretaria de Registros Acadêmicos do Centro de Ciências Humanas e da Educação (FAED), na UDESC. mentos e absorviam outros códigos culturais. De uma viagem, o viajante sempre voltava mais experiente ampliando e enriquecendo o seu universo cultural, suas relações sociais, de prestígio e conquistas profissionais (CARDOSO, 2011, p. 51).

Somando-se as essas experiências e supostamente pelo encantamento com projetos educacionais que conheceu, Jessy Cherem encontrou um campo fértil tanto para pôr em prática a fundação de jardins de infância - devido seu aperfeiçoamento no PABAEE-Inep -, como também para atuar na formação de professores(as). Essa condição foi possível pois "estes viajantes partiam com a intenção de observar, analisar, divulgar, comparar, propor e prescrever" (MIGNOT; GONDRA, 2007, p. 13).

Os deslocamentos realizados por Jessy Cherem podem ser observados em um movimento muito mais amplo, no qual as viagens educacionais ocorrem por diferentes motivações e em variados períodos. Serviam aos interesses de aproximar e intercambiar políticas e práticas educacionais, compra de mobiliários e objetos escolares, intercâmbios entre modelos educacionais e formação de professores.

No Brasil, as evidências dessas viagens pedagógicas remetem ao período colonial, “no qual é possivel observar a circulação de determinados autores e modelos educativos nesta América que se pretendeu aportuguesar (MIGNOT; GONDRA, 2007, p. 7). No período republicano, em especial no contexto das reformas educacionais ocorridas nos anos de 1920 e 1930, ocorreu um intenso movimento de conhecimentos e estratégias para renovar o quadro educacional brasileiro. Refletir sobre professores(as) viajantes em seus diferentes contextos permite identificar alguns traços biográficos, da atuação na vida pública, à frente de cargos e projetos educacionais.

Ao buscar vestígios sobre os deslocamentos de Jessy Cherem e, consequentemente, sua 
atuação no campo educacional, foi possivel identificar de forma parcial alguns locais por onde passou e as instituições em que atuou. A seguir, podem ser observadas algumas infor- mações referentes aos deslocamentos geográficos que realizou e os indicativos dos projetos educacionais e de sua atuação ao longo desse percurso.

Quadro 1 - Deslocamentos de Jessy Cherem (1950-1980)

\section{DESLOCAMENTOS: DATA, LOCAL DE ORIGEM E DESTINO}

\begin{tabular}{|c|c|}
\hline $\begin{array}{l}\text { DESLOCAMENTOS: DATA, LOCAL DE } \\
\text { ORIGEM E DESTINO }\end{array}$ & ATUAÇÃO PROFISSIONAL \\
\hline $\begin{array}{l}1951 \text { a 1958: saiu de Florianópolis com } \\
\text { destino a Curitiba. }\end{array}$ & $\begin{array}{l}\text { Atuou no Colégio Divina Providência (Curitiba), lecionando } \\
\text { aulas particulares de reforço em sua casa, e posteriormente } \\
\text { nas disciplinas sobre educação e vida em sociedade. }\end{array}$ \\
\hline $\begin{array}{l}\text { 1961: saiu de Curitiba e retornou para } \\
\text { Florianópolis. }\end{array}$ & $\begin{array}{l}\text { Período em que se efetivou na Secretaria Estadual de } \\
\text { Educação na função de Técnica Educacional. }\end{array}$ \\
\hline $\begin{array}{l}\text { 1962: viajou de Florianópolis para Belo } \\
\text { Horizonte. }\end{array}$ & Curso de aperfeiçoamento no PABAEE-Inep. \\
\hline $\begin{array}{l}\text { 1963: retornou de Belo Horizonte para } \\
\text { Florianópolis. }\end{array}$ & $\begin{array}{l}\text { Ao retornar a Florianópolis, foi designada para atuar na } \\
\text { Diretoria Municipal de Educação de Criciúma. }\end{array}$ \\
\hline $\begin{array}{l}1964 \text { a 1966: viajou de Florianópolis para } \\
\text { Criciúma. }\end{array}$ & $\begin{array}{l}\text { Nesses anos, atuou na Diretoria Municipal de Educação } \\
\text { de Criciúma, ministrou aulas no Colégio Madre Teresa, São } \\
\text { Bento, Marista, fundação do Jardim de Infância Pequeno } \\
\text { Príncipe e atuou na formação de professores(as). }\end{array}$ \\
\hline 1965-1973: realizou diversas viagens. & $\begin{array}{l}\text { Cursos de Psicologia com o professor Vilhena de Moraes: } \\
\text { Rio de Janeiro, São Paulo, Curitiba e diversas cidades de } \\
\text { Santa Catarina. }\end{array}$ \\
\hline $\begin{array}{l}\text { 1967-1969: viajou de Criciúma para } \\
\text { Curitiba. }\end{array}$ & Fundou o Jardim de Infância Tia Jessy, em Curitiba. \\
\hline $\begin{array}{l}\text { 1969-1970: viajou de Curitiba para o Rio } \\
\text { de Janeiro. }\end{array}$ & No Rio de Janeiro, fundou o Jardim de Infância Tia Gessy. \\
\hline $\begin{array}{l}\text { 1971: retornou de Curitiba para } \\
\text { Florianópolis. }\end{array}$ & $\begin{array}{l}\text { Retornou a Florianópolis e lá estabeleceu residência até } \\
\text { seu falecimento. Realizou graduação em Educação Artística } \\
\text { na UDESC (1980). }\end{array}$ \\
\hline 1983: em Florianópolis. & $\begin{array}{l}\text { Em 1983, fundou Jardim de Infância com sua colega de } \\
\text { curso Rosana Daux - Itaguaçu, bairro de Florianópolis. }\end{array}$ \\
\hline 1977-1987: em Florianópolis. & Tornou-se diretora do MHSC. \\
\hline
\end{tabular}

Fonte: elaborado pelas autoras com base em informações do arquivo pessoal de Jessy Cherem, nas entrevistas realizadas.

Ao longo de sua trajetória profissional, Jessy Cherem realizou muitas viagens, fixou residência cinco vezes em diversos locais, além de participar de diversas viagens de curta duração destinadas à formação de professores(as). Seu trânsito possibilita refletir sobre os múltiplos sentidos a que os deslocamentos podem ser atribuídos. Dimensionam também o espaço social que ocupou e as multiplicidades de trabalhos que realizou, muitas vezes ao mesmo tempo. Somam-se a isso sua condição de mulher, mãe, professora e viajante.

É importante destacar que, entre os anos de 1950 e 1980, quando Jessy realiza a maior parte de suas viagens educacionais, possivelmente enfrentou impedimentos e restrições, tanto pelas questões de gênero quanto provavelmente por ter realizado alguns desloca- 
mentos durante o regime de exceção, que teve início nos anos de 1964, com o golpe civil militar, até a redemocratização.

Em entrevista, Jessy comenta algumas situações inerentes a esse processo: “Em 1963 a cabeça das pessoas era muito diferente, e a separação de uma mulher jovem, eu tinha 28 anos. Pra mim foi muito difícil atravessar essa etapa. Criciúma era uma cidade muito pequena".22 Ao recordar de alguns episódios, relata que, quando residiu em Criciúma, era comum ir ao café que ficava ao lado da Catedral São José e próximo ao seu trabalho na prefeitura. Mesmo sendo prático para ela, pois era caminho de seu trabalho, recorda que

Uma vez encontrei Iracema que era esposa do proprietário do café, disse a ela:

- Iracema acho que não venho mais tomar meu cafezinho aqui, porque me sinto tão mal, vejo que as pessoas me reprovarem porque entro num café que é frequentado na maioria por homens e que mulher nenhuma entra para tomar café, só eu entro [...] Fui enfrentando, devagarinho fui enfrentando. Mas enfrentei muitas situações dificeis, muitas.

O comportamento prescrito e esperado para as mulheres era, ainda, de forma predominante, circunscrito às atividades domésticas, à criação dos filhos e cuidados aos idosos(as). Mãe de duas crianças, separada, experimentou a condição de mulher viajante. Enfrentou riscos e desconfortos de longas viagens, as dificuldades da chegada em lugares

\footnotetext{
12 As circunstâncias que trouxeram Jessy Cherem a Criciúma decorreram de motivações particulares, como também pela possibilidade de exercer sua contribuição profissional em outra cidade catarinense. Aliadas a desejos políticos de realizar o aperfeiçoamento das professoras normalistas e leigos no sul de Santa Catarina, criam-se as articulações necessárias para chegada da professora em Criciúma. Entre os atores, estavam Renato Ramos da Silva, senador pelo estado de Santa Catarina, de 1964 a 1967, pelo Partido Social Democrático (PSD); Arlindo Junkes, prefeito de Criciúma de 1963 a 1966, também pelo PSD; e Antônio Guglielmi Sobrinho, vereador de Criciúma de 1963 a 1966 e deputado estadual de Santa Catarina de 1967 a 1971, pela Aliança Renovadora Nacional (Arena).
}

novos, os desentendimentos fruto do desconhecido (CHAMON, 2015).

As questões narradas pela personagem fazem refletir sobre as situações que sofreu. Mesmo estando um espaço diferenciado em relação a grande parte das mulheres de seu tempo - mulher branca, pertencente à elite, professora primária e representante do governo para implementação de projetos educacionais -, não estava imune à "segregação sexual do espaço públicos" (PERROT, 1998), o que demonstram a existência de "lugares" praticamente proibidos às mulheres.

Ao vivenciar a condição de mulher viajante, experimentou também a condição de ser uma professora especialista em educação pré-primária pelo PABAEE-Inep, o que a qualificou para circular com representante do estado. Na medida em que foi realizando suas viagens educacionais, foi estabelecendo parcerias e atuando para criar jardins de infância. Além disso, a ausência de instituições educacionais pode ser considerada uma das razões que levaram a construir um itinerário de viagens.

Entre os múltiplos trânsitos realizados por Jessy Cherem, possivelmente o destinado ao curso do PABAEE-Inep, em Belo Horizonte, pode ser considerado uma experiência que se distingue das outras, por se tratar de uma viagem com duração de um ano e por se destinar a um período de dedicação a sua formação profissional. Assim como Jessy, professoras de diferentes estados brasileiros fizeram suas malas e seguiram rumo à capital mineira. Unidas por diferentes motivações, integraram o quadro de bolsistas do PABAEE-Inep. De acordo com dados apresentados por Paiva e Paixão (2002, p. 150), no relatório final elaborado pelos técnicos norte-americanos, o programa contou com a participação de 864 professores bolsistas entre os anos de 1959 e 1964, representando 25 estados brasileiros. A maioria dos 
participantes eram professoras, jovens normalistas e diretoras de escolas que se aventura- ram a cruzar fronteiras em busca de aperfeiçoamento profissional.

Figura 4 - Curso de aperfeiçoamento do PABAEE, em Belo Horizonte

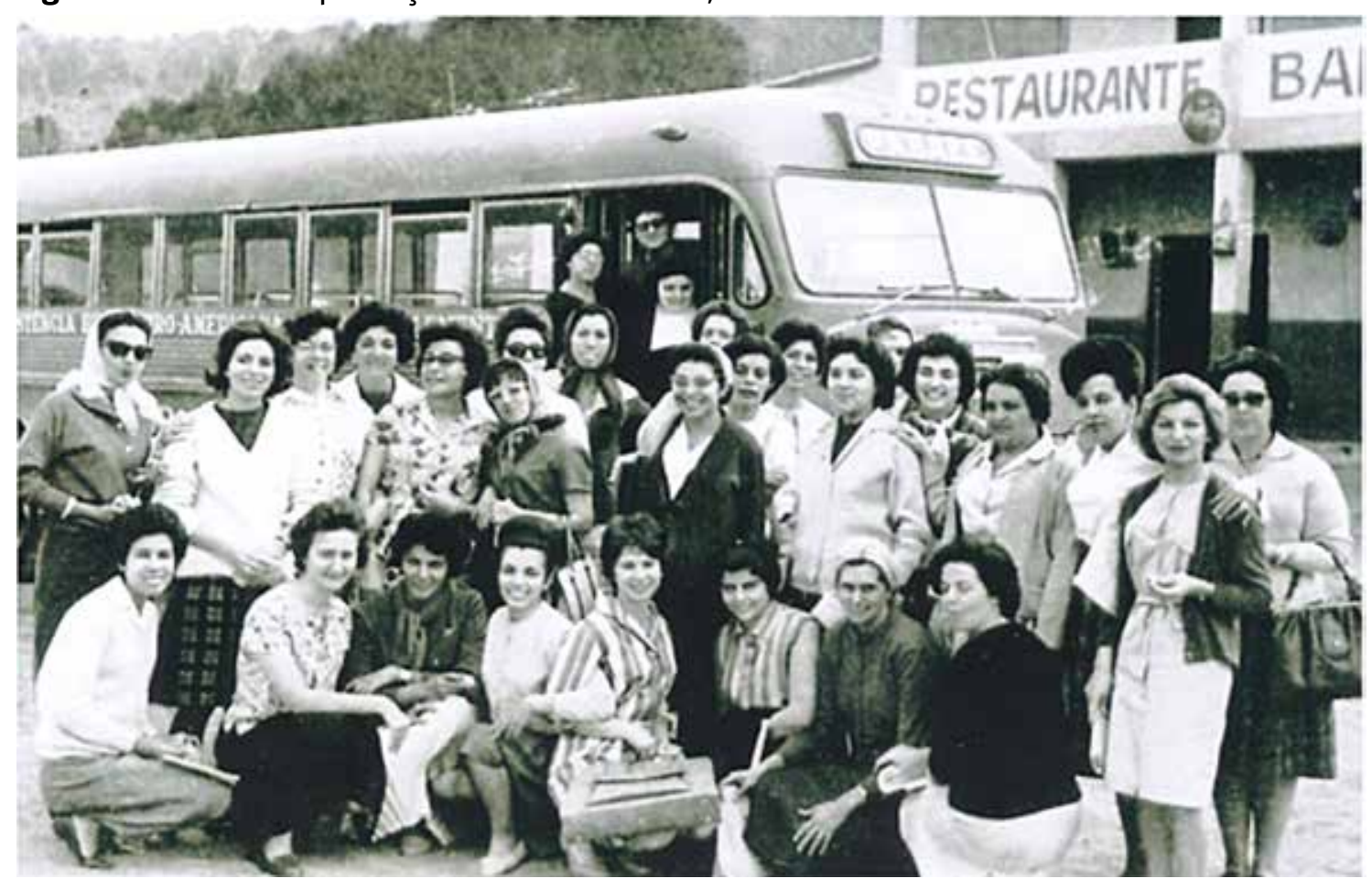

Agachada, da direita para esquerda, com suéter preto na primeira fileira, está Jessy Cherem.

Fonte: arquivo pessoal de Jessy Cherem, 1962.

Essas informações nos levam a pensar em quais seriam os critérios de seleção das professoras bolsistas. Como ocorreu a seleção de Jessy Cherem? Como ocorria a comunicação nas escolas para o encaminhamento de professores de todo o estado sobre a possibilidade de participação de cada professor-viajante?

De acordo com Fiori (2007), o secretário de Educação de Santa Catarina gozava de liberdade de escolha. Entretanto, seguia os critérios preestabelecidos pelo PABAEE, sendo os mais importantes deles: estar em sala de aula e ter experiência comprovada de mais de cinco anos. Outros critérios ficavam sob a responsabilidade dos estados, como:

Interesse pelo curso, disposição em permanecer na longínqua Belo Horizonte, competência revelada em atuação na rede de ensino ou no órgão central da Secretaria da Educação e, principalmente, compromisso com o governo no sentido de, após o retorno, atuar difundin- do os conhecimentos adquiridos mesmo no interior do estado, se necessário fosse. Mas a decisão definitiva sobre todo o assunto ficava no âmbito da vontade política do Secretário da Educação. Este realmente decidia quem teria a oportunidade de fazer o ambicionado curso (FIORI, 2007, p. 7).

Há informações, por meio das correspondências do programa, de que o crivo final das escolhas ficava sob o critério do Inep, instituição responsável por custear a participação dos professores. Sem saber ao certo as redes que propiciaram a seleção das professoras catarinenses, tem-se conhecimento de que Jessy foi uma das contempladas com a bolsa do PABAEE -Inep e que se inseriu no projeto pedagógico do programa como em um projeto de nação.

De acordo com oficios do PABAEE-Inep encaminhados aos estados brasileiros convocando a participação de professoras, os cursos funcionavam em período integral, cinco dias 
por semana. Em contrapartida, os bolsistas tinham seus salários mantidos pelos seus respectivos estados. ${ }^{13}$ Ao longo de seu afastamento, contavam ainda com ajuda de custo para estadia, além de receberem gratuitamente "farto" material didático, considerado moderno para os padrões da época.

No período em que permaneceram na capital mineira, essas professoras experienciaram leituras, debates educacionais e diferentes hábitos culturais - como diferentes dialetos e línguas, culinária, estilos musicais, entre outros -, para além do aperfeiçoamento educacional. Desse modo, ampliaram seus conhecimentos, estabeleceram relações e conviveram. Pode-se inferir que o trânsito dessas professoras oportunizou a ampliação do seu capital simbólico. Ou seja, o curso proporcionou não apenas um trânsito geográfico, mas também o modo como elas eram e conheciam, enriquecendo o que carregaram em suas bagagens após o PABAEE.

Esses elementos proporcionam pensar nessas mulheres permanecendo um ano longe de suas famílias, de seus afetos, de seus hábitos culturais. E imaginar ainda que possivelmente enfrentaram olhares de desconfiança, pois o ato de viajar sozinhas e, principalmente, hospedar-se em hotéis era ainda restrito às mulheres nos anos de 1960. Em entrevista a Fiori (2007), a personagem comenta aspectos sobre o cotidiano dos professores do PABAEE, da rotina de morar em um hotel, os passeios em algumas lojas e até mesmo as atividades de lazer que mantinham nas horas vagas. Jessy recorda que, aos sábados, ocorriam momentos destinados ao lazer, realizado nas casas dos professores norte-americanos, dedicados a conversar, embalados por músicas e lanches. Sobre tais eventos, Jessy Cherem, em entrevista concedida a Fiori (2007, p. 10-11), comenta:

13 No caso de Jessy Cherem, como era técnica educacional vinculada à Secretaria de Educação do Estado de Santa Catarina, permaneceu recebendo seu salário como servidora.
[...] o interessante é que nós recebíamos um convite escrito que marcava a hora de entrada e a hora de saída dessa reunião. E tínhamos que respeitar essa disciplina de horário imposta pelos professores americanos. A professora Nazi$\mathrm{ra}^{14}$ só ficava dizendo: 'por favor, não cheguem tarde'. Era muito interessante. Quando o relógio chegava pertinho de 10 horas, todos já iam pegando as suas coisas e tratando de se despedir.

Tais indícios chamam a atenção e criam possibilidades para refletir sobre os convites para uma simples confraternização de professores, os quais delimitavam o horário de término da ocasião. Teriam prescrições de etiqueta e civilidade? Havia uma forma de controlar a circulação das jovens professoras em relação à presença de professores e dos técnicos educacionais norte-americanos (geralmente homens)?

As entrevistas possibilitam acumular pistas do cotidiano das professoras bolsistas do PABAEE-Inep, transitando entre estados e municípios, quando cruzam fronteiras sociais e culturais. 0 trânsito dessas professoras registra marcas das discussões e teorias educacionais, pois muitas professoras normalistas possuíam uma educação com traços da forte presença católica. Já as discussões e teorias do programa vinculavam-se à educação com viés da laicidade.

\section{Pelo percurso muitas possibilidades}

Investigar os deslocamentos de Jessy Cherem foi um importante movimento de pesquisa que possibilitou construir sentidos ao seu viver, além de permitir conhecer sua trajetória, traçando aspectos sobre a formação de professores, campanhas educacionais, cenários e cotidianos vivenciados não apenas por ela, mas por diversas outras professoras viajantes.

14 Nazira Feres Abi-Saber, diretora do Departamento de Pré-primário, responsável pela formação do PABAEE em jardins de infância. 
Para além de seus deslocamentos, elas, em suas bagagens, carregavam conhecimentos adquiridos que thes autorizavam atuar como representantes do estado na tarefa de aperfeiçoamento de outros professores, produzindo, assim, marcas de um fazer educacional em sintonia com o PABAEE-Inep. Tal iniciativa, pouco estudada, não proporcionou para muitas dessas mulheres o reconhecimento tanto na história da educação quanto delas como mulheres públicas. Bourdieu (2004, p. 35-36) considera que:

As lutas pelo reconhecimento são uma dimensão fundamental da vida social e de que nelas está em jogo a acumulação de uma forma particular de capital, a honra no sentido da reputação, de prestígio, havendo, portanto, uma lógica específica da acumulação e no reconhecimento.

A trajetória de Jessy Cherem permite conjecturar e refletir sobre uma possivel invisibilidade das mulheres, ao mesmo tempo em que desempenharam protagonismo no âmbito das políticas de formação, sobretudo daquelas que atuaram em diversos cargos na esfera pública e à frente de grandes campanhas educacionais. São mulheres que circularam, adquirindo e construindo experiências, e, por meio de seus aperfeiçoamentos, conquistaram distinção em relação a outros professores de sua época. Muitas delas, pertencentes a elites, já transitavam em jantares e salões da alta sociedade; entretanto, suas presenças nesses ambientes domésticos não foram suficientes para garantir a imortalização de seus nomes e feitos - a exemplos de muitos professores e intelectuais homens. São mulheres pouco lembradas, mencionadas e pesquisadas.

Além disso, é importante considerar, no horizonte das viagens, que elas produziram efeitos também no campo das sensibilidades, ao propiciar reflexões sobre as dificuldades e possiveis estranhamentos enfrentados por es- sas professoras nesse período. Apesar de um cenário com forte presença modernizante, em uma sociedade com vistas a transformações, na qual a educação era cada vez mais encorajada, a presença de centenas de professoras hospedadas na capital mineira para os cursos de aperfeiçoamento do PABAEE-Inep indica um duplo movimento: mulheres que estão firmando posições, desempenhando papéis na esfera social e, por outro lado, enfrentando os desafios do reconhecimento nos espaços públicos, ainda refratários a algumas práticas profissionais para o sexo feminino.

A escolha da palavra "trânsito", referente aos percursos realizados por Jessy Cherem, foi pensada a partir das possibilidades abertas pela própria palavra, no sentido amplo tanto relacionado ao ato de transitar como ao de circular. Reflete sobre como essas viagens possivelmente proporcionaram contatos e deslocamentos no campo das concepções educacionais entre o ser "tradicional" e o transitar para uma pedagogia "renovadora", entre "ser professora normalista" e ser "representante do governo", entre tantos outros deslocamentos, como o trânsito entre a esfera do privado para a vida pública, culminando na ampliação de horizontes de expectativa nos círculos sociais, nas amizades, nas paixões, entre muitas outras possibilidades.

\section{Referências}

AURAS, Gladys Mary Teive. Modernização econômica e formação do professor em Santa Catarina. Florianópolis. Editora UFSC, 1998.

AVELAR, Alexandre de Sá; SCHMIDT, Benito Bisso (org.). Grafia da vida. Reflexões e experiências com a escrita biográfica. São Paulo: Letra e Voz, 2012.

BATISTA, Rosa. A emergência da docência na educação infantil no estado de Santa Catarina: 1908 - 1949. 2013. 198 f. Tese (Doutorado em Educação) - Universidade Federal de Santa Catarina. Florianó- 
polis, 2013. Disponivel em: https://repositorio.ufsc. br/xmlui/handle/123456789/122863. Acesso em: 23 mar. 2019.

BOURDIEU, Pierre. Coisas Ditas. Tradução de Cássia R. da Silveira e Denise Moreno Pegorim; Revisão técnica Paula Montero. São Paulo: Brasiliense, 2004.

CARDOSO, Silmara de Fátima. Viajar é inventar o futuro: narrativas de formação e o ideário educacional brasileiro nos diários e relatórios de Anísio Teixeira em viagem à Europa e aos Estados Unidos (1925-1927). 2011. 158 f. Dissertação (Mestrado em Educação) - Programa de Pós-Graduação em Educação, Faculdade de Educação da Universidade de São Paulo. São Paulo, 2011. Disponivel em: http:// www.teses.usp.br/teses/disponiveis/48/48134/ tde-17052011-163245/publico/SILMARA_DE_FATIMA_ CARDOSO.pdf. Acesso em: 26 jul. 2018.

CHAMON, Carla Simone. Itinerários de uma professora em fins do século XIX. In: ORLANDO, E. A.; SILVA, A. L.; DANTAS, M. J. (org.). Mulheres em trânsito: intercâmbios, formação docente, circulação de saberes e práticas pedagógicas. Curitiba: CRV, 2015. p. 109-124.

\section{CHAMON, Carla Simone. Maria Guilhermina Loureiro}

de Andrade: a trajetória profissional de uma educadora (1869-1913). 2008. 338 f. Tese (Doutorado em Educação) - Faculdade de Educação, Universidade Federal de Minas Gerais. Belo Horizonte, 2008.

COELHO JUNIOR, Nelson Maurilio. Entre a caneta do legislador e a vigilância do inspetor: as correspondências de Elpídio Barbosa no arquivo do Colégio Coração de Jesus (Florianópolis, 1939/1949). Tese (Doutorado em Educação) - Programa de Pós-Graduação em Educação. UDESC, 2018.

CUNHA, Maria Teresa Santos. 0 arquivo pessoal do professor catarinense Elpídio Barbosa (1909-1966): do traçado manual ao registro digital. História da Educação, Porto Alegre, v. 21, p. 187-206, jan./abr. 2017. Disponivel em: http://dx.doi.org/10.1590/22363459/66723. Acesso em: 27 mar. 2020.

FIORI, Neide Almeida. O Programa Brasileiro-Americano de Assistência ao Ensino Elementar (PABAEE) segundo memórias de uma aluna/professora. In: CONGRESSO INTERNACIONAL DE EDUCAÇÃO PEDA-
GOGIAS (ENTRE) LUGARES E SABERES, 5. Anais [...]. São Leopoldo, 2007.

GOMES, Ângela de Castro. 0 Brasil de JK. 2. ed. Rio de Janeiro: FGV, 1991.

HEINZ, Flavio M. (org.). Por outra história das elites. Rio de Janeiro: FGV, 2006.

HEYMANN, Luciana Quillet. O lugar do arquivo: a construção do legado de Darcy Ribeiro. Rio de Janeiro: FAPERJ, 2012.

HOBBS, Catherine. 0 caráter dos arquivos pessoais: reflexões sobre o valor dos documentos de indivíduos. In: HEYMANN, Luciana Quillet; NEDEL, Letícia (org.). Pensar os arquivos: uma antologia. Rio de Janeiro: FGV, 2018. p. 261-274.

MAURíCIO, Lúcia Velloso. A opção pelo magistério representada por professoras de ensino fundamental em memoriais. Educação em Revista, Belo Horizonte, v. 25, n. 1, p. 115-138, abr. 2009.

MAY, Patrícia Zumblick Santos. Redes político-empresariais de Santa Catarina (1961-1970). 1998. 182 f. Dissertação (Mestrado em História Cultural) - Programa de Pós-graduação em História. Florianópolis: Universidade Federal de Santa Catarina; Centro de Filosofia e Ciências Humanas, 1998.

MIGNOT, Ana Chrytina Venâncio; GONDRA, José Gonçalves. Viagens pedagógicas. São Paulo: Cortez, 2007.

PAIVA, Edil Vasconcellos; PAIXÃO, Léa Pinheiro. PABAEE (1956-1964): a americanização do ensino elementar no Brasil? Niterói: UFF, 2002.

PEDRO, Joana Maria. Mulheres honestas e mulheres faladas uma questão de classe. Florianópolis: UFSC, 1994.

PERROT, Michele. Mulheres públicas. São Paulo: Unesp, 1998.

SILVA, Vera Lucia Gaspar da. Sentidos da profissão docente: estudo comparado acerca de sentidos da profissão do ensino primário, envolvendo Santa Catarina, São Paulo e Portugal na virada do século XIX para o século XX. São Paulo: FEUSP, 2004, tese de doutorado. 
SOUZA, Elizeu Clementino (org.). Memória, (auto) biografia e diversidade: questões de método e trabalho docente. Salvador: UFBA, 2011.

VIANNA, Claudia Pereira. A feminização do magistério na educação básica e os desafios para a prática e a identidade coletiva docente. In: YANNOULAS, Silvia Cristina (org.). Trabalhadoras: análise da feminização das profissões e ocupações. Brasília: Abaré, 2013. p. 159-180.

WASCHINEWESKI, SUsane Costa. Biblioteca de orientação da professora primária: as regras de civilidade no conteúdo de Estudos Sociais do Programa de Assistência Brasileiro-Americana ao Ensino Elementar - PABAEE (1956-1964). 2017. 152 f. Dissertação (Mestrado em Educação) - Programa de Pós-Graduação em Educação. Criciúma: UNESC, 2017. Disponível em: http:// repositorio.unesc.net/bitstream/1/5151/1/ SUSANE\%20DA\%20COSTA\%20WASCHINEWESKI.pdf. Acesso em: 27 mar. 2020.

\section{Decreto}

SANTA CATARINA. Secretaria da Justiça, Educação e Saúde. Departamento de Educação. Decreto n. 3735, de 17 de dezembro de 1946. Estabelece o regulamento para os estabelecimentos de ensino primário no Estado de Santa Catarina. Florianópolis, 1947.

Recebido em: 06.10.2019

Revisado em 25.03.2020

Aprovado em: 27.03 .2020

Susane da Costa Waschinewski é Doutoranda do Programa de Pós-Graduação em Educação da Universidade do Estado de Santa Catarina (UDESC). Mestra em Educação pela Universidade do Extremo Sul Catarinense (UNESC). Graduada em Geografia pela UNESC. Membro do grupo de pesquisa Arquivos Pessoais, Patrimônio e Educação. E-mail: sucosta@ unesc.net

Maria Teresa Santos Cunha é Professora titular do Departamento e do Programa de Pós-Graduação em História e em Educação da Universidade Estadual de Santa Catarina (UDESC). Doutora em Educação pela Universidade de São Paulo (USP). Mestra e graduada em História pela Universidade Federal de Santa Catarina (UFSC). Vice-líder do grupo de pesquisa Arquivos Pessoais, Patrimônio e Educação. Bolsista Produtividade em Pesquisa 1-D, pelo Conselho Nacional de Desenvolvimento Científico e Tecnológico (CNPq).E-mail: mariatsc@gmail.com 